\title{
Design of Mobile Operation and Maintenance System Based on Power GIS and GPS
}

\author{
TAO Jing ${ }^{1,2, *}$, WU Liwen $^{3}$, ZHANG Yanlei ${ }^{3}$, ZHANG Jiaojiao ${ }^{3}$ and YAO Jiming i $^{1,2}$ \\ ${ }^{1}$ Global Energy Interconnection Research institute, Nanjing, China \\ ${ }^{2}$ State Grid Laboratory of Electric Power Communication Network Technology, Beijing, China \\ ${ }^{3}$ Information \& Telecommunication Company, State Grid Jibei Electric Power Co., Ltd, Beijing, China
}

\begin{abstract}
In order to solve the low efficiency of operation and maintenance and the problems of management coordination caused by the coexistence of off-line operation and maintenance and multi system coexistence in current power telecommunication operation and maintenance, this paper proposes a mobile operation and maintenance system based on power GIS and GPS location technology. The system is based on the $\mathrm{C} / \mathrm{S}$ architecture, and the mobile operation and maintenance terminal is connected with the operation and maintenance management terminal through wireless and wired network. In addition to meeting basic business requirements, the system integrates power GIS functions to visually demonstrate communication resources, personnel, and failures. The staff can use the wireless mobile terminal which integrated GPS module for to operate and maintain, and can locate accurately in real time.
\end{abstract}

\section{Introduction}

The operation and maintenance of power communication is a series of comprehensive management in order to ensure the stable operation of power system. Mainly include: (1)Communication scheduling (such as system operations monitoring, fault management, communication resource management, etc.), (2) The operation of communication (analysis of power communication data, technical management, safety management, etc.), (3) Maintenance of communication (such as daily information collection, regular inspection, troubleshooting, etc.).

Currently, the following problems exist in the implementation and management of power communication and maintenance operations:

-Lack of unified management platform. The management modes, software, hardware systems and media forms adopted by different provinces and cities are different. Multi mode coexistence does not facilitate centralized management of all communication systems under the state Power Grid Corp, and discrete data can easily lead to information silos,

-Part of the communication operation and communication service is still off-line. First, the management system distributes the work order to the operation and maintenance operator, and then the operator carries the printed work order to inspects and records simultaneous, and finally enters the check result into the system. This method reduces the efficiency of the operation and maintenance operator, and increases the verification workload of the management administrator. And the description of the fault or the hidden danger depends on the personal written expression ability of the operation and maintenance personnel,

-Lack of intuitive map display. Localization of communication resources, fault and maintenance personnel patrol record respectively depend on management accounting, fault report written description and work logs. When needed, the communication resources, failures and maintenance personnel can't be quickly located.

To solve the above problems, a mobile operation and maintenance system based on power GIS, GPS positioning and IOT identification is designed and applied to the field of power communication operation and maintenance.

\section{System design}

\subsection{System overall design}

Corresponding author: taojing@geiri.sgec.com.cn 


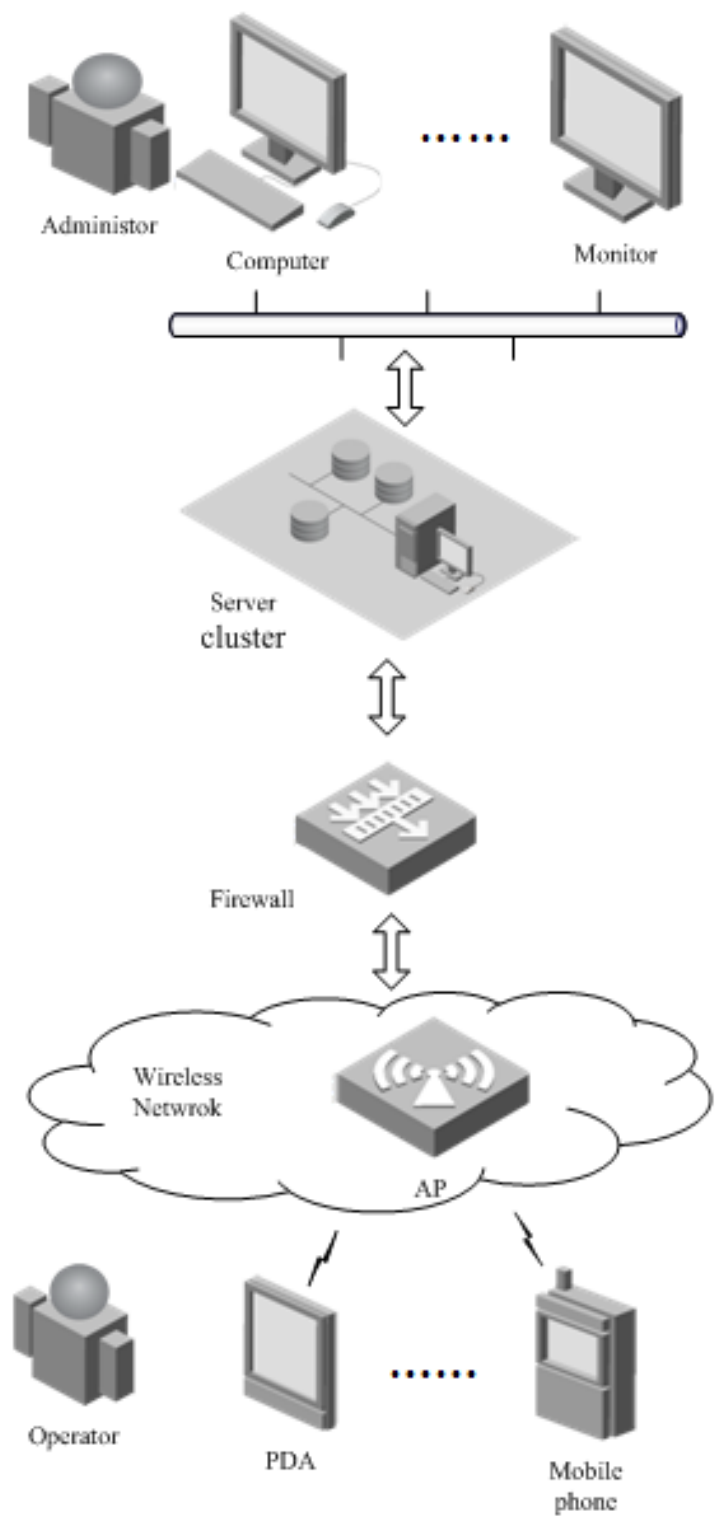

Fig. 1. Design of mobile operation and maintenance system.

Operators on the spot use mobile terminals for operation and maintenance, and mobile terminals use wireless VPN to access the wireless network via AP. Wireless networks connect to the VPN firewall. Depending on the security area which operation and maintenance data belongs, the data will be connected to the server cluster after the firewall of a specific security zone. Server cluster includes mobile operation and maintenance server, data server and so on. Management terminals connect to the server through network devices such as switches.

\subsection{Function of Mobile Terminal}

The mobile terminal contains the following hardware modules: GPS positioning module, wireless communication module, button module, processor module, power module, multimedia module and memory module. The processing module implements the software function of the mobile terminal, including terminal management, signal processing, data encryption, log management, security management, streaming media and information push. As shown in Fig 2:

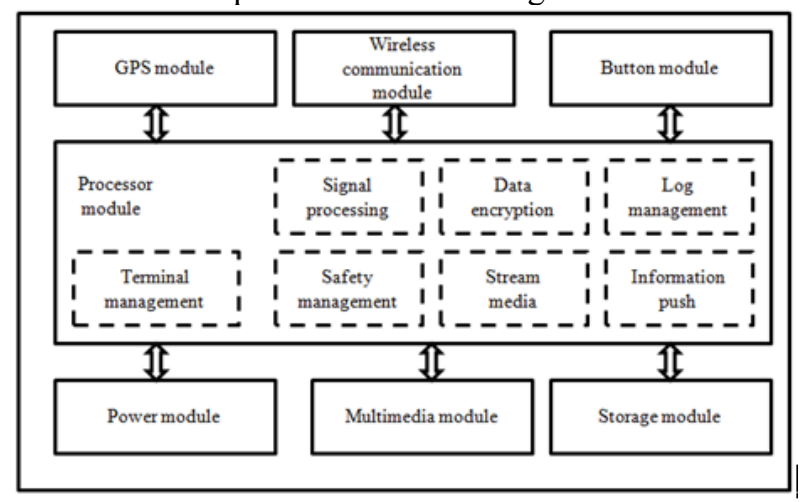

Fig. 2. Design of mobile terminal

Operators receive the work orders distributed by the management terminal through the mobile terminal, and respond accordingly. Operators performs maintenance operations on the spot according to the pushed checklist, safety notices and operation instructions issued in the mobile terminal, and reports communication equipment, circuit status and other information in real time. When the operation and maintenance site is found to be out of order or need to be dealt with online, it can be communicated with other operators or managers through the online call and online video module of the mobile terminal. As shown in the following figure:

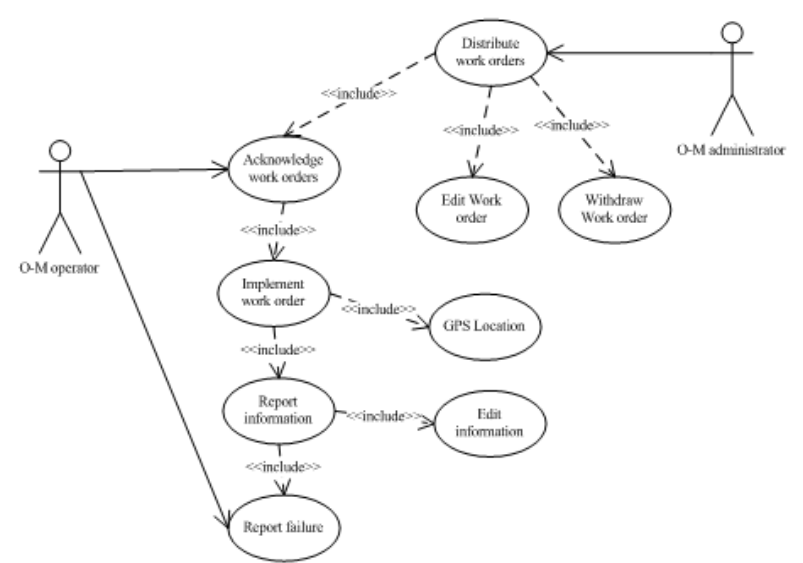

Fig. 3. UML use case diagram for work order execution.

\subsection{Function of Management Terminal}

The management terminal includes the following hardware modules: additional function interface, additional data interface, communication module, processor module, power module, multimedia module, data server. The processing module implements the software function of the management terminal, including signal processing, data encryption, network management, personnel management, Yun Wei plan management, report management, fault management, resource management, communication management, streaming media information release, GIS management, Yun Wei system management, terminal management, 
log management and security management. As shown in figure 4:

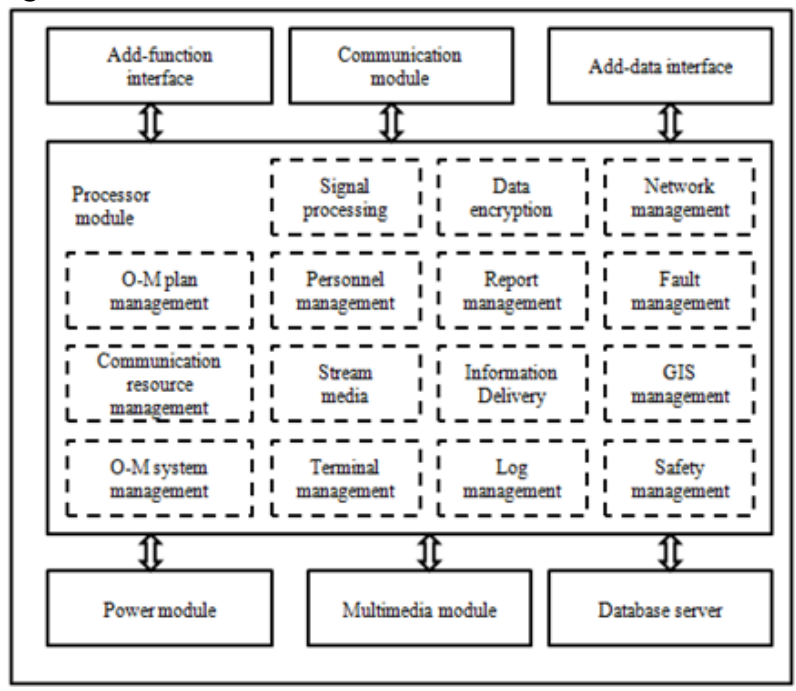

Fig. 4. Design of Management terminal.

In the overall coordination of scheduling: by using the management of terminals, the administrator can plan the operation and maintenance and manage all communication resources in the system, and also be able to control the failure and line status, generate corresponding reports according to different levels and requirements.

In management of a single task: the administrator distribute the work order to operator. And then, the administrator can inquire the current position of the personnel and the implementation of the plan through the personnel management module and the operation and maintenance plan management module.

\section{Application of key technologies in the system}

\subsection{System Problems and Solutions}

In order to solve the problems faced by the current operation and maintenance in the introduction and improve the intelligence level of the equipment, the mobile operation and maintenance system not only realizes the basic functions, but also focuses on the research and implementation of the following functions: -Visual display. This function helps to improve the readability of all types of reports. In the event of a failure, the affected area and line can be viewed intuitively through the management terminal, and the operators can be dispatched to the scene as soon as possible. The operator can quickly query to the fault location through the mobile side. And ultimately reduce the duration of the failure.

-The high-precision positioning function of mobile terminal. This function helps to locate the fault quickly, manage the communication resources, and check the working discipline of the operators.

-Intelligent communication resource identification and marking. Using more efficient and intelligent equipment or line identification technology to avoid errors caused by manual registration. And after that, the status of the current resources can be recorded online, and the historical information can accessed in real time, so as to improve the efficiency of communication resource management.

In order to achieve the above functions, the system uses the power GIS, GPS positioning, Internet of things equipment identification technology.

\subsection{Application of Key Technologies}

\subsubsection{Power GIS}

GIS (Geographic Information System) is a data management system that can centralize, store, query, edit, process and display geographic information. Power GIS is an example of GIS in the application of power system, can integrate and display the roads, ordinary buildings, power system construction (such as substations and power plants etc.), tower, transmission line, communication resources (such as communication equipment, communication lines etc.) with realistic geographical environment.

In the mobile operation and maintenance system, both the server management and the mobile terminal can perform the visual fault tracking and resource scheduling through the power GIS function. As shown in the following figure:

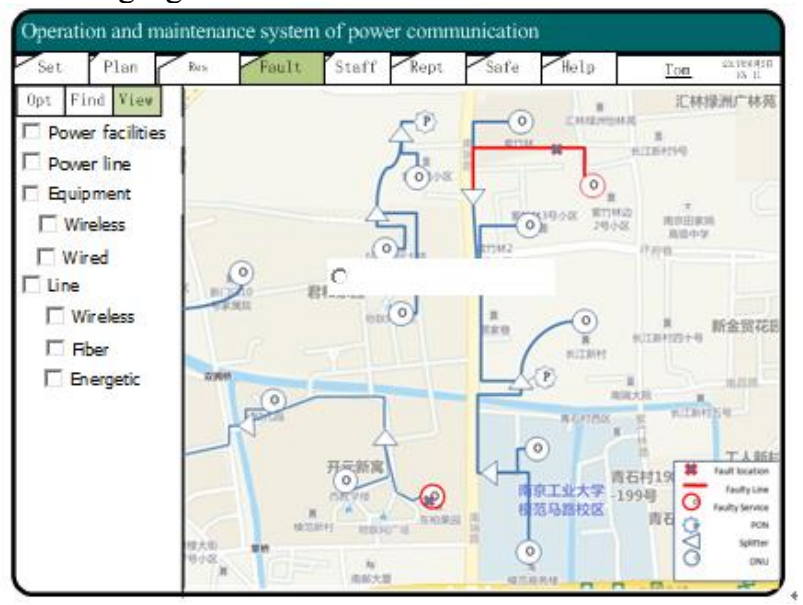

Fig. 5. The GIS view of the fault on Management Terminal. 


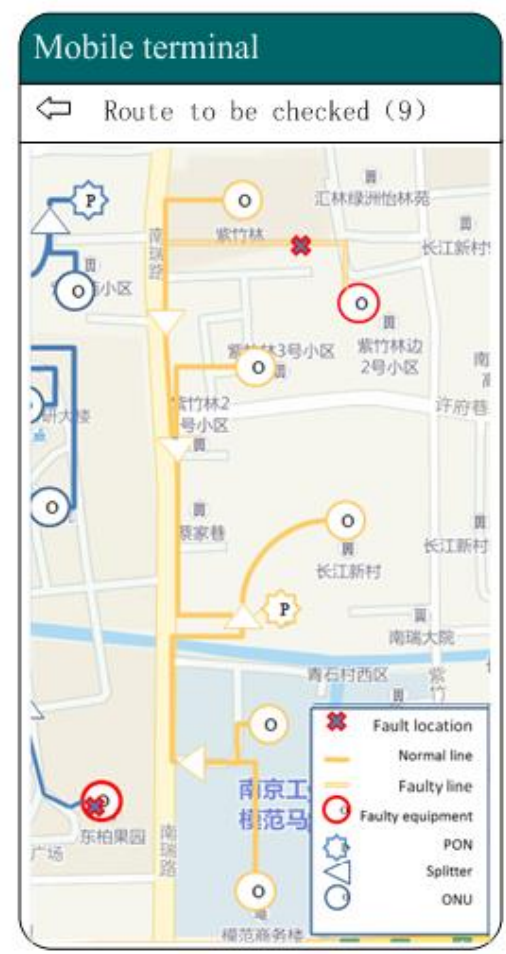

Fig. 6. Routes to be checked on Mobile Terminal.

\subsubsection{GPS}

In order to realize the high precision and real-time positioning of mobile terminals, several mainstream localization technologies are investigated. The advantages and disadvantages are shown in the following table:

Table 1. Comparison Of Several Positioning Techniques.

\begin{tabular}{|l|l|l|}
\hline $\begin{array}{l}\text { Positioning } \\
\text { Technology }\end{array}$ & \multicolumn{1}{|c|}{ Virtues } & \multicolumn{1}{c|}{ Flaws } \\
\hline GPS & $\begin{array}{l}\text { Technology is } \\
\text { mature and module } \\
\text { prices are low. }\end{array}$ & $\begin{array}{l}\text { Positioning takes a long } \\
\text { time (about a few } \\
\text { minutes), civilian } \\
\text { accuracy is low (about } \\
10 \mathrm{~m}), \quad \begin{array}{l}\text { indoor } \\
\text { positioning effect is } \\
\text { poor. }\end{array}\end{array}$ \\
\hline A-GPS & $\begin{array}{l}\text { Quick positioning, } \\
\text { moderate civilian } \\
\text { accuracy (5m or } \\
\text { so). }\end{array}$ & $\begin{array}{l}\text { Wireless cellular base } \\
\text { station networks are } \\
\text { needed, the use of A- } \\
\text { GPS requires a fee. }\end{array}$ \\
\hline Wifi AP & $\begin{array}{l}\text { It is economical and } \\
\text { practical without } \\
\text { adding hardware } \\
\text { modules }\end{array}$ & $\begin{array}{l}\text { Clients are required to } \\
\text { connect to the wireless } \\
\text { network }\end{array}$ \\
\hline FRID & $\begin{array}{l}\text { Indoor positioning } \\
\text { can be achieved }\end{array}$ & $\begin{array}{l}\text { The location accuracy } \\
\text { is low and the } \\
\text { workload of the } \\
\text { deployment location } \\
\text { network is large }\end{array}$ \\
\hline
\end{tabular}

In consideration of : 1) most of the power communication operation and maintenance work is carried out on the ground, and the technology of supporting outdoor positioning can be selected; 2) the operation and maintenance work has its own duration, so rapid positioning is not necessary; 3 ) combined with the power GIS, the accuracy of $10 \mathrm{~m}$ has met the use requirements; 4) convenience and economy. Therefore, this system finally selects the GPS positioning technology. Figure 7 shows the interface when the operators fill in the patrol record:

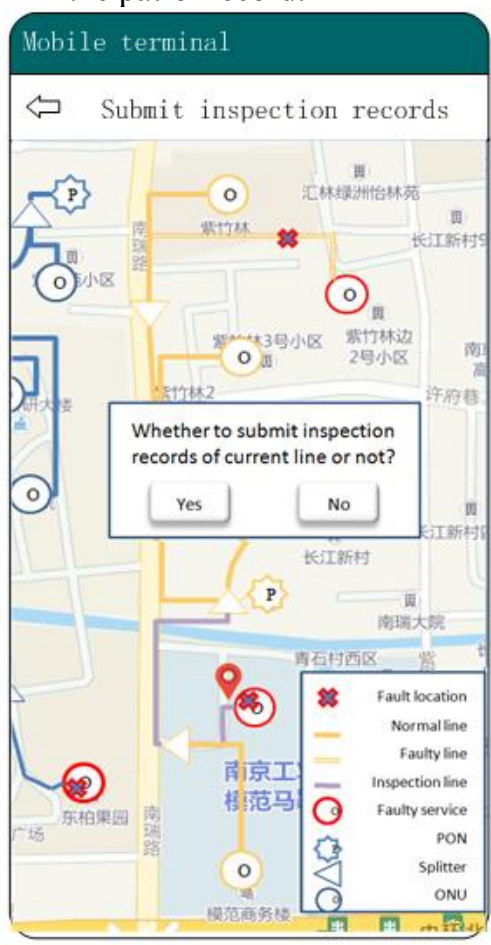

Fig. 7. Record submission

\subsubsection{IOT Device Identification Technology}

The Internet of things identification technology can query and edit the communication resource information rapidly on the mobile terminal, and can maintain all the historical information of the resource through the database at the management server. The current mainstream equipment identification technologies, including bar code, two-dimensional code and radio frequency identification technology, are investigated. Considering the difficulty and cost of the implementation, the bar code and two-dimensional code identification methods are selected.

The bar code capacity on the fixed assets label of the existing communication equipment and circuit can be expanded or replaced into two-dimensional codes. At the operation and maintenance site, the operator scans the bar code or two-dimensional code through the camera assembled by the mobile terminal and enters the information base of the resource. Operators update the corresponding attributes of the resources according to the actual situation at the scene. The management terminal updates the information to the data server to avoid the emergence of information islands.

\section{Summary}

The design can solve the current power communication operation and maintenance encountered in a series of problems. In order to ensure the stability of power grid 
and communication network operation, the design proposed in this paper adopts the mature technology. The extended function and data interface are reserved in the software and hardware modules of the terminal, so as to improve the adaptability of the device.

In addition, the design of mobile terminal and management terminal in this article is based on independent device, so it contains hardware module and software. In actual $\mathrm{R} \& \mathrm{D}$ and production, a large number of investigations are needed to determine the specific forms of implementation. Such as mobile side installs applications installed in Android, IOS and other system terminals, the management side installs executable programs in Windows, Linux and other systems.

\section{Acknowledgment}

This work was supported by the Science and Technology Foundation of the State Grid Corporation of China: Research and demonstration application of intelligent operation and maintenance for power communication field(SGJBXT00DDJS1700067).

\section{References}

1. YANG Guoqi. Consideration on construction of power telecommunication operation and maintenance system[J]. Communication world, 2017, 10:154-155.

2. YANG Zhimin, HUANG Yu, LEI Yun, etc. Power communication, operation and maintenance, mobile system and power communication operation and maintenance method:, CN 103685215 A[P]. 2014.

3. CHEN Dong, TU Li, LI Huimin, etc. Design of comprehensive operations automation system of power transmission and transformation equipment[J], Electrical Measurement \& Instrumentation,2016, 53(2):1-9.

4. GAo Xiaoming. Design and Research of Power Equipment Inspection System Based on Mobile Internet[D].South China University of Technology,2013

5. SHI Wenbo, YU Junjie, LI Xiaoxiao. Design and realization of electric power GIS system[J]. Modern Electronics Technique, 2015, 38(21):155-158.

6. HU Shengqing. Research on fast positioning of optical fiber cable fault in power system based on GIS[J]. China High-tech Enterprises, 2016(35):7-8.

7. BI Jingxue, ZHEN Jie, GUO Ying. Accuracy of GPS and A-GPS Positioning on Android Phone[J]. Bulletin of Surveying and Mapping, 2016(7):10-13.

8. Shen Li, Bi Wei, Shu Kaiqi. Design of GPS and GP R S based remote synchronization detector[J] Electrical Measurement \& Instrumentation, 2016, 53(21):124-128.
9. HUANG Hongbing, LIU Junyi. Management, technology, double pipe drive to improve the quality of power communication operation and maintenance $[\mathrm{J}]$. Enterprise Management, 2016(S1):270-271.

10. KUANG Hong-hai, ZHANG Shu-yun, ZENG Liqiong, etc. Design of rural intelligent distribution network remote monitoring system based on GPRS and GPS[J]. Advanced Technology of Electrical Engineering and Energy, 2017(4):83-88.

11. ZHANG Jing, ZHANG Qingwei, WANG Kaiyu, etc. Research on RFID positioning technology applied to Internet of Things devices[J]. Modern Electronics Technique, 2017, 40(5):29-32.

12. JIANG Shu. Comparative study on the application of bar code, two-dimensional code and RFID in archives management[J]. Beijing archives, 2015(8):36-37.

13. XIAO Qingwang, WANG Jinhua, ZHU Yixiang. Intelligent terminal device identification method of internet of things $[\mathrm{J}]$. Telecommunications Science, 2017, 33(2):3-8. 